\title{
Relationship Between Cognitive Functions and Online Game Addiction
}

\author{
Nikita Yadav ${ }^{1 *}$
}

\section{ABSTRACT}

The present study was aimed to examine the cognitive functions among adolescents with online game addiction behaviour. For the present study 60 adolescents who play online games were been studied living in Delhi-Ncr region following cross-sectional research design. The instruments used encompassed of a demographic data sheet, Game addiction scale, Stroop color word test, Trail making test, Eysenck's series of digit span test and n-beck test. The obtained data was been analysed by using SPSS to see the relationship between cognitive functions and game addiction with Pearson-r, frequency distribution and correlation. The findings indicated that gamers who remained preoccupied with playing had difficulty in color naming and indicates withdrawal feature that interfere in their retrieval. And also indicates that online gamers who experienced conflict due to online gaming had significantly deficit in attention and concentration.

\section{Keywords: Cognitive Functions, Game Addiction, Online Game}

$\mathrm{B}$ ehavioral addiction occurs when the person feels compelled to engage in an action that is rewarding even if there are negative consequences to his or her physical, mental, social, or financial well-being.

Apart from ingestion of psychoactive substances, a variety of behaviors produce short-term rewards that can encourage persistent behavior despite knowledge of adverse outcomes. A key feature of psychoactive substance dependency or addiction is diminished control. The same analogy has given rise to the concept of "behavioral" addictions, i.e., syndromes comparable to substance addiction, but without the ingestion of a psychoactive substance as the central focus. There is some scientific and clinical elucidation of behavioral addictions, but the notion remains controversial. There are many debates that are currently circulating in the context of the development of DSM-V about behavioral addictions.

The most recent version of the Diagnostic and Statistical Manual of Mental Disorders (DSM-5) enlists only one behavioural addiction (gambling disorder), three behavioural compulsions (hoarding disorder, trichotillomania, and excoriation), and one impulse-control

\footnotetext{
${ }^{1}$ Research scholar, Department of Clinical Psychology, Faculty of Behavioural Sciences, SGT University, Gurugram, Haryana, India

*Corresponding Author

Received: October 07, 2021; Revision Received: November 20, 2021; Accepted: December 08, 2021

(C) 2021, Yadav N.; licensee IJIP. This is an Open Access Research distributed under the terms of the Creative Commons Attribution License (www.creativecommons.org/licenses/by/2.0), which permits unrestricted use, distribution, and reproduction in any Medium, provided the original work is properly cited.
} 
disorder (kleptomania). However, there are some traits that are common to all behavioural addictions, including

- Behavior preoccupation.

- Difficulty controlling behaviors.

- Acquiring a tolerance to the behavior

- In cases of avoidance or resistance, experiencing withdrawal.

- The behavior avoidance or resistance can have adverse psychological consequences such as depression or anxiety symptoms

\section{Game Addiction (GD):}

Sometimes referred to as video game addiction/disorder. According to APA 2013, "It is a persistent and recurrent use of the Internet to engage in games, often with other players, leading to clinically significant impairment or distress" as indicated by five (or more) of the following in a 12-month period: "1. Preoccupation; 2. Withdrawal; 3. Tolerance; 4. Loss of control; 5. Loss of non-gaming interests; 6. Gaming despite harms; 7. Deception of others about gaming; 8. Gaming for escape or mood relief; 9. Conflict/interference due to gaming. It typically takes at least 12 months for these features and the underlying pattern of online gaming to become apparent before a diagnosis can be assigned, although this period may be shortened if all diagnostic requirements are met and symptoms are severe. It may include both online and offline gaming types, although the online is much more common. A diagnosis can typically be assigned after at least 12 months of the symptoms and the pattern of games. However, if all diagnostic requirements are met and the symptoms are severe, the duration may be shortened. Both online and offline gaming types fall under GD, although online versions are considered to be more common.

\section{Prevalence of game addiction:}

Prevalence estimates have been found to vary, mostly due to differences in sample characteristics (e.g., gender, age), cultural and geographical differences (e.g., Asian versus non-Asian countries, urban versus rural locales), and methods chosen for screening. In general, these studies have reported prevalence rates ranging between $1 \%$ and $2 \%$. Recent studies from Mihara and Higuchi (2017) investigated the prevalence of IGD across 37 crosssectional and 13 longitudinal studies. They found that IGD prevalence ranged from $0.7 \%$ to $27.5 \%$, with the most extreme figures (i.e., $>5 \%$ ) reported from nonrepresentative samples. The prevalence of IGD was higher among males than females in the majority of studies, and it tended to affect younger individuals over older ones.

The effect of video game playing (Boot et al, 2008) examined both expert/non-gamer differences and video game playing's effects on tasks involving a wider range of cognitive abilities, such as attention, memory, and executive control. Non-gamers played action games, puzzle games, or real-time strategy games for more than 20 hours. Expert gamers and non-gamers demonstrated different levels of basic cognitive skills: experts tracked objects moving at greater speeds, detected changes to objects in their visual short-term memory, switched tasks more quickly, and mentally rotated objects more effectively. It is striking to see that playing video games did not substantially improve performance for nongamers on most cognitive tasks; however, they did perform better on mental rotation. The findings suggested that some differences in basic cognitive performance between video game experts and non-gamers can be attributed either to greater video game experience or to pre-existing group differences that result in a self-selection effect. 


\section{Cognitive Development of skills:}

1. Problem solving/decision-making skills: Traditionally, video games train problem solving and strategy development by getting the player to solve increasingly difficult problems. Often, there is time pressure, which enhances speed and decision-making ability. There are some studies that show young people play video games to enhance their creativity as well.

2. Strategy development: Playing video games predominantly exercises the brain. It usually involves working out a strategy to either stay alive or defeat the boss; construct a structure or blow it up. As such, it is considered a highly active pastime, at least on the cognitive level. It has been acknowledged by a number of researchers and clinicians, and video game principles are still being used in training situations, rehabilitation and cognitive development exercises.

3. Attention Allocation skills: Game players have faster, more accurate attentional skills, enabling them to make more informed decisions and weigh up where their attention should be at any given time for how long.

4. Spatial Skills: A spatial ability is a category of reasoning skills that refers to an individual's ability to think in three dimensions and to draw conclusions about objects based on a limited amount of information. With good spatial abilities, a person might also be able to determine how an object will appear when rotated. Skills such as these are useful in a variety of real-life situations and can be acquired through practice. Science, technology, engineering, and mathematics require spatial thinking skills.

\section{REVIEW OF LITERATURE}

Park et al (2011) investigated differences in cognitive functioning between persons addicted to the Internet and those who were not addicts using neuropsychological testing. A total of 253 middle school students and 389 high school students were tested for Internet addiction and their IQs were compared with 59 Internet-addicted and 43 non-addicted peers. The internet-addicted group scored significantly lower on the comprehension sub-item than the non-addicted group. Since a comprehension item involves ethical judgment and reality checking, there may exist a connection between Internet addiction and poor social intelligence. There is an association between earlier onset of Internet addiction and a longer duration of addiction and lower performance in areas relating to attention. Since this study was cross-sectional in nature, it was unclear whether the individuals with poor cognitive functioning are susceptible to Internet addiction or whether Internet addiction causes cognitive problems. Although brain development remains active during adolescence, it cannot be ruled out that Internet addiction negatively affects adolescent cognitive development.

Polak et al (2016) examined changes in addiction symptoms following outpatient treatment for IGD and associated improvements in QOL and cognitive functioning. The study included 84 young males (IGD group: $\mathrm{N}=44$, mean age: 19.159 years; healthy control group: $\mathrm{N}=40$, mean age: 21.375 years). To assess clinical and psychological characteristics, self-reported questionnaires at baseline were administered, and traditional and computerized neuropsychological tests were administered. After six months of outpatient treatment, including pharmacotherapy with selective serotonin reuptake inhibitors, 19 patients with IGD underwent follow-up tests in the same way. Compared with the healthy control group, patients with IGD displayed higher levels of depression and anxiety, impulsiveness, anger, and distress, as well as poorer quality of life and impaired response inhibition. During the first 6 months after being treated for IGD, patients showed significant improvements in their 
symptoms as well as in their QOL, response inhibition, and executive function. Additionally, stepwise multiple regression analysis indicated that IGD patients with low working memory capacity and high executive function could expect a good prognosis. The findings provide evidence regarding changes in QOL and cognitive function following psychiatric intervention for IGD. Further, it appears that inhibition of the response is one of the objective markers underlying the pathophysiology of IGD.

Tekin et al (2018) The study investigated the relationship between Internet Addiction (IA) and cognitive functions by using the Stroop and Trail Making Tests. It involved 221 university students. First, the participants filled out a socio-demographic questionnaire and the Internet Addiction Scale (IAS). In the second step, individuals with and without IA were administered the Stroop Test (ST), Trail Making Test (TMT), and Beck Depression Inventory (BDI). Results revealed that 15.3 percent of the participants had IA $(n=34)$. Four participants who had IA refused to participate in the second step. IAS score was positively correlated with Stroop Phonemic time, Stroop Color Naming time, Stroop Interference time, TMT-B form time and TMT-B form false number (respectively; $\mathrm{r}=.31, \mathrm{r}=.50, \mathrm{r}=.46, \mathrm{r}=.39$ and $\mathrm{r}=.66$ ). The results suggested that attention-related problems and problems with controlling behavior may be related to IA.

Aliyari et al (2018) studied the effects of video games on players' stress levels based on their style of play. There were 80 players, aged 18 to 30 years, who played four types of video games: Runner, Excitement, Fear, and Puzzle. SPSS and Matlab systems were used to analyze the data (after and before video game play). According to the research results, salivary amylase levels increased significantly after playing the Fear, Runner, and Excitement games, and decreased significantly after playing the Puzzle game. Additionally, salivary cortisol concentration increased significantly after playing the Runner game, Excitement game, and Fear game, and decreased significantly after playing the Puzzle game. The brain wave analysis also revealed that playing Fear game resulted in higher levels of stress than playing Excitement game. Research findings concluded that, video games can affect the stress system as well as the cognitive system of humans depending on the game style. Furthermore, depending on the type and level of stress triggered by the game, different types of players experience different effects.

\section{Need of present study:}

Multiple studies suggest that Internet addiction may be linked to certain cognitive conditions. There is an increase in recognition of internet gaming disorder as a social problem across countries and negatively affects the quality of life and cognitive function. A number of cognitive tasks were found to be more effective for action video gamers than nonplayers. This relationship, however, could not be readily established in several failed attempts to replicate the benefits of video game players. Furthermore, despite the discovery that problematic video game players demonstrate lower performance levels than nonproblematic gamers on multiple objects tracking paradigms, this has not been investigated for other tasks. According to recent research, there is a relationship between cognitive functions and online game addiction; the severity of game addiction on cognitive functions influences adolescence with game addiction. The present study intends to confirm that there is no relationship between cognition and addiction to online games. 
METHODOLOGY

The present study was aimed to examine the cognitive functions among adolescents with online game addiction behaviour.

\section{Objective}

To study the relationship between cognitive functions and online game addiction.

\section{Hypothesis}

There would be no significant relationship between cognitive functions and online game addiction.

\section{Sample}

For the present study 60 adolescents who play online games were been studied living in Delhi-Ncr region following cross-sectional research design.

\section{Instruments}

Five measures were used in this study,

1. Game addiction scale (GAS): To measure respondent's degree of pathological gaming, a seven-item game addiction scale developed by Lemmens et al, 2009 was used, which is based on the DSM IV-criteria for pathological gambling previously adapted by Griffiths (2005). There are two versions, the long version has 21 questions and the short version has only 7 . Both have a high level of reliability and in the present study 21 item scale was used, which had 7 criteria (Salience, tolerance, mood modification, withdrawal, relapse, conflict, and problems) with three-item each randomly been distributed over the scale. It had items on a 5-point continuum scale ranging from 1 (never), 2 (rarely), 3 (sometimes), 4 (often), and 5 (very often).

2. Eysenck's series of digit span test (ESDST): ESDST is used to check person's attention and concentration by using a number of series, in which the participant is asked to repeat the numbers in same order as the researcher says. The number list starts from 3 digit number and lasts upto 8 digit number. After this the participant is asked to repeat the number in backward order. For example: If researcher says 2,5 then the participant repeats 5,2. The number list starts from 2 digit number and lasts upto 8 digit number.

3. Trail making test (TMT): In 1938, Partington and Leiter developed Trail Making Test (TMT) to measure divided attention and was originally used in Army Individual Test Battery (Partington \& Leiter, 1949) by the U.S. Army (Army Individual Tests Battery, 1944). Later, it was included in the Halstead-Reitan Neuropsychological Battery (Reitan, 1955a). This test consists of two parts (TMT-A and TMT-B). It measures attention, speed, and mental flexibility. It also measures spatial organization, visual pursuit, recall, and recognition. Part A requires the participant to draw lines to connect 25 encircled numbers scattered across the page. In Part A, you will also be tested on visual scanning, numeric sequencing, and visuomotor speed. A similar test can be found in Part B, but during that section the person alternates between numbers and letters and that part is reputed to be more difficult and take longer to complete. In Part B, mental flexibility, motor skills, and visual spatial abilities all are assessed. The duration of both sections is measured, and the score represents how much time it takes to complete each one.

4. Stroop Color and Word Test (SCWT): A neuropsychological test widely used both in research and for clinical purposes. The test assesses a person's ability to 
prevent cognitive interference, which is a phenomenon where the processing of one feature of a stimulus can interfere with the processing of another. In the most common version of the SCWT, which was originally designed by Stroop in 1935, subjects have to read three different tables as quickly as possible. It presents two "congruous conditions" where participants must read names of colors printed in black ink (W) and name different colored patches $(\mathrm{C})$. In the third table, the colorword $(\mathrm{CW})$ condition, the color-words are printed in varying colors of ink (for instance, the color "red" is printed in green). As a result, in this incongruent condition, participants must name the color of the ink rather than read the word. This means that the participants are required to perform a task that is not highly automated (such as naming ink colours), while inhibiting the interference that could arise from a more automated task. It is known as the Stroop effect that makes it difficult to stop an automated process. Despite widespread use of the SCWT for assessing cognitive interference, previous literature also discusses its application for evaluating attention, processing speed, cognitive flexibility, and working memory. As a result, the SCWT may be used to measure cognitive function across multiple domains.

5. N-Beck Test: This is a working memory test, used to measure the participant recent working memory in which the researcher reads out alphabets letters one by one in a gap of 2 seconds. The participant has to listen to it carefully and tell the researcher whenever a letter repeats one after other. For example: A_D_A_N in this the participant had to tell the pairing AA. There are 17 pairing in total and participant have to report as much as s/he can.

\section{Procedure}

The data was collected through standardized questionnaire after distribution of questionnaire instructions were given to respondents as per the manual of respective test scoring of responses was done according to manual. The obtained data was been analysed by using SPSS to see the relationship between cognitive functions and game addiction with Pearson-r, frequency distribution and correlation.

RESULTS
$\begin{aligned} & \text { Table No. } 1 \text { showing the sample characteristics of the data (frequency distribution \& } \\
& \text { percentage) }\end{aligned}$
\begin{tabular}{|l|l|l|}
\hline Variable & N(Percentage) \\
\hline \multirow{2}{*}{ Gender } & Male & $28(46.7)$ \\
\cline { 2 - 3 } & Female & $32(53.3)$ \\
\hline \multirow{3}{*}{ SES } & Middle & $59(98.3)$ \\
\cline { 2 - 3 } & Upper Class & $1(1.7)$ \\
\hline \multirow{3}{*}{ Resident } & Rural & $2(3.3)$ \\
\cline { 2 - 3 } & Urban & $41(68.3)$ \\
\cline { 2 - 3 } & Semi-Urban & $17(28.3)$ \\
\hline \multirow{2}{*}{$\begin{array}{c}\text { Type of } \\
\text { family }\end{array}$} & Nuclear & $38(63 \%)$ \\
\cline { 2 - 3 } & Joint & $21(35 \%)$ \\
\cline { 2 - 3 } & Extended & $1(15 \%)$ \\
\hline
\end{tabular}

Table 1 shows the sample characteristics of data using frequency distribution \& percentage. It shows that most of the sample was female $(46.7 \%)$ belongs to middle socio-economic status $(98.3 \%)$, resides in urban areas $(68.3 \%)$ and belong to nuclear families $(63 \%)$. 
Table No. 2 showing the clinical characteristics of the sample (Mean \pm SD)

\begin{tabular}{|l|l|}
\hline Variable & Mean \pm SD \\
\hline Age of onset & $14.98 \pm 3.28$ \\
\hline Time spend (per day) & $4.13 \pm 5.94$ \\
\hline Total duration (in months) & $58.15 \pm 32.04$ \\
\hline
\end{tabular}

Table 2 shows the clinical characteristics of the sample which has mean age of sample onset as $14.98 \pm 3.28$. The mean time spend per day was $4.13 \pm 5.94$ and total duration since started playing game was found to be $58.15 \pm 32.04$.

Table No. 3 showing the clinical characteristics of the sample (Frequency \& Percentage)

\begin{tabular}{|l|l|l|}
\hline Variable & N $(\%)$ \\
\hline \multirow{4}{*}{$\begin{array}{l}\text { Mode of game } \\
\text { behaving }\end{array}$} & Online & $23(38.3 \%)$ \\
\cline { 2 - 3 } & Offline & $3(5 \%)$ \\
\cline { 2 - 3 } & Both & $34(56.7 \%)$ \\
\hline \multirow{2}{*}{ Problem faced } & Group & $5(8.3 \%)$ \\
\cline { 2 - 3 } & Individual & $18(30.0 \%)$ \\
\cline { 2 - 3 } & Both & $37(61.7 \%)$ \\
\cline { 2 - 3 } & Yes & $12(20 \%)$ \\
\hline
\end{tabular}

Table 3 shows the clinical characteristics of the sample resulting that most of the subjects $(57 \%)$ plays online games, preferring to play individually as well as in group $(61.7 \%)$ from which $80 \%$ have faced no problem while playing.

Table No. 4 showing the relationship between online game behaviour and strop test (Pearson-r)

\begin{tabular}{|l|l|l|l|l|}
\hline Variable & Stroop word & Stroop color & $\begin{array}{l}\text { Stroop color } \\
\text { word }\end{array}$ & Interference \\
\hline Salience & 0.10 & $0.27^{*}$ & 0.18 & 0.006 \\
\hline Tolerance & -0.02 & 0.13 & 0.11 & -0.04 \\
\hline $\begin{array}{l}\text { Mood } \\
\text { modification }\end{array}$ & -0.15 & -0.03 & -0.07 & 0.05 \\
\hline Relapse & 0.02 & 0.10 & 0.08 & 0.05 \\
\hline Withdrawal & 0.15 & 0.09 & $0.31^{*}$ & $-0.25^{*}$ \\
\hline Conflict & -0.02 & 0.19 & 0.05 & 0.08 \\
\hline Problems & 0.03 & 0.17 & 0.05 & 0.16 \\
\hline
\end{tabular}

Table 4 shows the relationship between online game behaviour and stroop test using pearson-r method of positive correlation between salience and stroop color (0.27), withdrawal and stroop color word (0.31). And negatively correlated with withdrawal and interference (-0.25).

Table No. 5 showing the relationship between online game behaviour and trail making test (Pearson-r)

\begin{tabular}{|l|l|l|}
\hline Variable & Trail making A & Trail making B \\
\hline Salience & -0.02 & 0.02 \\
\hline Tolerance & 0.01 & 0.12 \\
\hline
\end{tabular}


Relationship Between Cognitive Functions and Online Game Addiction

\begin{tabular}{|l|l|l|}
\hline Variable & Trail making A & Trail making B \\
\hline Mood modification & 0.00 & 0.21 \\
\hline Relapse & 0.14 & 0.10 \\
\hline Withdrawal & -0.04 & -0.16 \\
\hline Conflict & 0.02 & -0.02 \\
\hline Problems & 0.24 & 0.10 \\
\hline
\end{tabular}

Table 5 shows that there is no correlation between trail making test and online game addiction.

Table No. 6 showing the relationship between online game and digit forward and digit backward test (Pearson-r)

\begin{tabular}{|l|l|l|}
\hline Variable & Digit forward & Digit backward \\
\hline Salience & 0.09 & 0.03 \\
\hline Tolerance & 0.08 & -0.23 \\
\hline Mood modification & -0.50 & $-0.42^{*}$ \\
\hline Relapse & -0.07 & -0.08 \\
\hline Withdrawal & 0.01 & -0.08 \\
\hline Conflict & -0.09 & $-0.27^{*}$ \\
\hline Problems & -0.04 & -0.24 \\
\hline
\end{tabular}

Table 6 shows the relationship between online game and digit forward \& backward test using pearson-r method of correlation. The results show negative correlation between mood modification and digit backward (-0.42) and conflict and digit backward (-0.27).

Table No. 7 showing the relationship between online game and n-beck test (Pearson-r)

\begin{tabular}{|l|l|l|}
\hline Variable & N-Beck Hit & N-Beck Miss \\
\hline Salience & 0.05 & -0.05 \\
\hline Tolerance & -0.04 & 0.04 \\
\hline Mood modification & 0.06 & -0.06 \\
\hline Relapse & -0.16 & 0.16 \\
\hline Withdrawal & -0.03 & 0.03 \\
\hline Conflict & 0.08 & -0.08 \\
\hline Problems & -0.21 & 0.21 \\
\hline
\end{tabular}

Table7 shows that there is no significant relationship between n-beck test and online game addiction.

\section{DISCUSSION}

Behaviour addiction refers to several mental health conditions in which the person engages in a particular behaviour repeatedly, even if the behaviour causes the harm, they cannot resist engaging in it. Common behaviour addiction includes gaming addiction, shopping addiction, impulsive stealing etc. Gaming addiction is one of the most common behaviour addictions in the current period. Game challenges our mental skills in a way that performance in other tasks involving some activities improves. Playing games can develop the cognitive skills of an individual like problem-solving, decision-making skills, attention allocation skills, spatial skills etc. 
The previous research findings Tekin et.al (2018) have shown that an important rate of internet addiction was found between internet addiction scale score and stroop and trail making test scores and indicates no significant difference in prevalence og internet addiction between genders.

The present research findings show that stroop color was significantly correlated with salience. It indicates that gamers who remained preoccupied with playing had difficulty in color naming.

On the other hand, withdrawal found to be significantly associated with color word and interference. It indicates that, those who played online game experiences withdrawal feature and that interfere in their retrieval.

Whereas, mood modification was found to be significantly negatively associated with digit backward which indicates that online gamers who experience mood modification due to online game are unable to relax and feel happy.

And conflict was found to be significantly negatively associated with digit backward, which indicates that online gamers who experienced conflict due to online gaming had significantly deficit in attention and concentration.

\section{CONCLUSION}

The findings indicate that gamers who remained preoccupied with playing had difficulty in color naming and indicates withdrawal feature that interfere in their retrieval. And also indicates that online gamers who experienced conflict due to online gaming had significantly deficit in attention and concentration.

\section{REFERENCES}

Aliyari, H., Sahraei, H., Daliri, M. R., Minaei-Bidgoli, B., Kazemi, M., Agaei, H., Sahraei, M., Hosseini, S., Hadipour, M. M., Mohammadi, M., \& Dehghanimohammadabadi, Z. (2018) "The Beneficial or Harmful Effects of Computer Game Stress on Cognitive Functions of Players", Basic and clinical neuroscience, 9(3), 177-186. https://doi.org/10.29252/nirp.bcn.9.3.177

American Psychiatric Association. (2013). Diagnostic and statistical manual of mental disorders (5th ed.). https://doi.org/10.1176/appi.books.9780890425596

Boot, W. R., Kramer, A. F., Simons, D. J., Fabiani, M., \& Gratton, G. (2008). The effects of video game playing on attention, memory, and executive control. Acta psychologica, 129(3), 387-398. https://doi.org/10.1016/j.actpsy.2008.09.005

Granic, I., Lobel, A., \& Engels, R. C. M. E. (2014). The benefits of playing video games. American Psychologist, 69(1), 66-78. doi:10.1037/a0034857

Grant JE, Potenza MN, Weinstein A, Gorelick DA. Introduction to behavioral addictions. Am J Drug Alcohol Abuse. 2010;36(5):233-241. doi:10.3109/00952990.2010.491884

King, D. L., \& Delfabbro, P. H. (2020). Video game addiction. Adolescent Addiction, 185213. doi:10.1016/b978-0-12-818626-8.00007-4

Lemmens, J. S., Valkenburg, P. M., \& Peter, J. (2009). Development and Validation of a Game Addiction Scale for Adolescents. Media Psychology, 12(1), 77-95. doi:10.1080/15213260802669458

Llinàs-Reglà, J., Vilalta-Franch, J., López-Pousa, S., Calvó-Perxas, L., Torrents Rodas, D., \& Garre-Olmo, J. (2017). The Trail Making Test. Assessment, 24(2), 183-196. https://doi.org/10.1177/1073191115602552 
Lim, J. A., Lee, J. Y., Jung, H. Y., Sohn, B. K., Choi, S. W., Kim, Y. J., Kim, D. J., \& Choi, J. S. (2016) "Changes of quality of life and cognitive function in individuals with Internet gaming disorder: A 6-month follow-up", Medicine, 95(50), e5695. https://doi.org/10.1097/MD.0000000000005695

Mihara, S., \& Higuchi, S. (2017). Cross-sectional and longitudinal epidemiological studies of Internet gaming disorder: A systematic review of the literature. Psychiatry and Clinical Neurosciences, 71(7), 425-444. doi:10.1111/pcn.12532

Park, M. H., Park, E. J., Choi, J., Chai, S., Lee, J. H., Lee, C., \& Kim, D. J. (2011) "Preliminary study of Internet addiction and cognitive function in adolescents based on IQ tests", Psychiatry research, 190(2-3), 275-281. https://doi.org/10.1016/j.psychres.2011.08.006

Scarpina, F., \& Tagini, S. (2017). The Stroop Color and Word Test. Frontiers in psychology, 8, 557. https://doi.org/10.3389/fpsyg.2017.00557

Tekin, Atilla \& Yetkin Tekin, Aysegul \& Adiguzel, Serkan \& Akman, Hakan. (2018) "Evaluation of Stroop and Trail-Making Tests Performance in university students with Internet Addiction", Anadolu Psikiyatri Dergisi. 19. 10.5455/apd.292389. https://doi.org/10.5455/apd.292389

\section{Acknowledgement}

The author appreciates all those who have participated in the study and helped to facilitate the research process.

\section{Conflict of Interest}

The author(s) declared no conflict of interest.

How to cite this article: Yadav N. (2021). Relationship Between Cognitive Functions and Online Game Addiction. International Journal of Indian Psychology, 9(4), 1185-1194. DIP:18.01.112.20210904, DOI:10.25215/0904.112 